\title{
Influence Mechanism of Window-to-Wall Ratio on Energy Consumption of Rural Buildings in Southern Shaanxi, China
}

\author{
Xiaoling Cui, Shuaibing Yin, Lei Zhang, Yiyun Zhu*, Guochen Sang, Qin Zhao \\ School of Civil Engineering and Architecture, Xi'an University of Technology, Xi'an 710048, China
}

Corresponding Author Email: zyyun@xaut.edu.cn

https://doi.org/10.18280/ijht.370225

Received: 25 December 2018

Accepted: 9 March 2019

\section{Keywords:}

rural buildings in southern Shaanxi, building energy consumption, windowto-wall ratio $(W W R)$, orientation, heat transfer coefficient

\begin{abstract}
In order to improve the of the indoor thermal environment quality of rural residential buildings in southern Shaanxi, China, a calculation model for the typical brick-concrete residential building in that area was established based on field survey results. A dynamic simulation was carried out to determine how the window-to-wall ratio (WWR) of different orientations and the heat transfer coefficient of the window affect the total energy consumption of the typical building in the study area, as well as the energy consumed in cooling and heating. The results show that, with the increase in the WWR of any orientation, the building consumed more energy in cooling and fewer energy in heating; the optimal window orientation in the study area should be south, north, east and west; in order to save energy, the south-facing WWR should fall within $0.3 \sim 0.7$, the east-facing WWR should stay below 0.7 , and the west-facing wall should not have any window or have a small window; the building energy consumption could be reduced by enhancing the insulation performance of the window, and the reduction rate increased with the WWR, especially with the east- or west- facing WWR.
\end{abstract}

\section{INTRODUCTION}

Currently, buildings consume $30 \%$ to $43 \%$ of the total energy consumed in Chinese society [1-3]. The energy consumption of a building depends on its envelope. Doors and windows, as the main openings on building envelope, are weak in heat preservation and insulation of the building. Through the two components, the thermal energy can easily flow out of the building via radiation, convection, conduction and air leakage. Thus, doors and windows have a direct impact on the energy efficiency of the building and the quality of indoor thermal environment.

The typical envelope of buildings consists of door(s), windows, walls, roof and floor. The doors and windows consume 3 times, 4 times and over 19 times more energy than the walls, the roof and the floor, respectively in China. In total, the two components account for $40 \sim 50 \%$ of the total energy consumption of building envelope and $15 \%$ 20\% of that of the entire society [4-5]. Therefore, it is very meaningful to explore how building energy consumption is affected by the various parameters of windows (e.g. orientation, window-to-wall ratio (WWR), heat transfer coefficient, shading coefficient and external sunshade) under the conditions of the local climate zone.

In five distinctive climate zones of China (See Figure 1), the window parameters like the WWR, heat transfer coefficient and shading coefficient have different degrees of impact on building energy consumption [6]. Among them, the WWR is a leading impactor. The hot summer and cold winter zone cover 16 provincial administrative regions, taking up $18.8 \%$ of Chinese territory. As the name suggests, this zone has humid and hot summers and wet and cold winters, showing different energy demand from the other four regions. The WWR in this zone is gradually increasing with time for better natural lighting and ventilation performance. In some cases, the WWR is as high as 0.61 [7]. The large WWR hinders the energy conservation of buildings. Therefore, it is necessary to investigate the effects of different WWRs on building energy consumption across this zone.

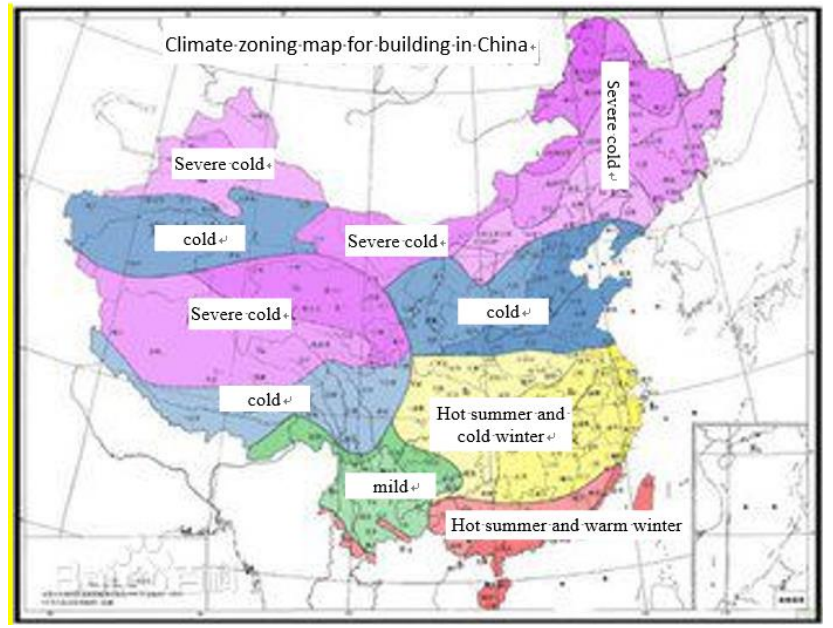

Figure 1. Climate zoning for buildings in China

Many scholars have explored the relationship between the WWR and building energy consumption in hot summer and cold winter zone. Through the analysis on a residential building in Shanghai, Jian and Jiang [8] suggests that the building consumed more energy with increasing the WWR in the east (west) and north directions, and the energy consumption of the building decreased by increasing the south-facing WWR, after adopting external sunshield and effective night ventilation in summer. Yan et al. [9] examines 
a typical residential building in Ningbo, and reveals that the building energy consumption increased with the WWR of each orientation, especially the east- and south-facing WWRs. Focusing a room with $\mathrm{AN}$ inverter air-conditioner (AC), chen et al. [10] discovers that the energy consumption grew exponentially with the increase in the WWR, the growth rate was much faster at the WWR of 0.52 0.58 than at the WWR of $0.33 \sim 0.37$, and the predicted mean vote (PMV) fluctuated more violently with the increase in the WWR. Meng et al. and Cheng et al. [11, 12] respectively investigate the typical residential buildings in Nanjing and other areas in southern Jiangsu, and draw the following conclusions: The AC energy consumption and total energy consumption of residential buildings increased with the WWR; the relationship between the energy consumed for heating and the WWR depends on the insulation performance of the windows (the relationship is positive if the windows had poor insulation performance, and negative if the windows had good insulation performance); the annual energy consumption of buildings decreased with the heat transfer coefficient, and the decrement rate grew with the WWR. Focusing on residential buildings in Changsha, Hunan and the other three cities, Jiang [13] points out that the northfacing WWR had the smallest impact on AC and heating energy consumptions, while the south-facing WWR had the greatest impact on AC energy consumption; the smallest annual total energy consumption could be achieved at the south-facing WWR of 0.3 ; the insulation performance of windows affects the influence degree of the WWR on heating energy consumption, but not the influence degree of the WWR on total energy consumption. Fan et al. [7] explores the energy consumption of the main room in typical rural buildings of the hot summer and cold winter zone, and thus obtains the optimal south-facing WWR as 0.28 0.41.

According to the above studies, the influence of the WWR on building energy consumption basically follows the same trend across the hot summer and cold winter zone. However, the trend may vary and even reverse in particular areas. Thus, it is necessary to study the buildings in areas with specific climate features. In this paper, the rural buildings in Hanzhong Prefecture, southern Shaanxi, are taken as the research objects. The field survey and numerical simulation were integrated to disclose how the WWR and the thermal performance of windows affect building energy consumption. The research findings provide references for improving the indoor thermal environment of rural buildings in the study area.

\section{CURRENT STATUS OF RURAL BUILDINGS IN HANZHONG PREFECTURE}

Hanzhong Prefecture (N: 32 $08^{\prime} 54^{\prime \prime} \sim 33^{\circ} 53^{\prime} 16^{\prime \prime} ;$ E: $105^{\circ} 30^{\prime} 50^{\prime \prime} \sim 108^{\circ} 16^{\prime} 45^{\prime \prime}$ ) is a hilly area located on the north of the Daba Mountain and on the south of the Qinling Mountain. In summer, the area has a small diurnal temperature variation and tends to be windless in most days; the mean outdoor air temperature is $31.8^{\circ} \mathrm{C}$ and the relative humidity is $59.1 \%$. In winter, the mean outdoor air temperature is $4.6^{\circ} \mathrm{C}$ and the relative humidity is $71.4 \%$. With a high air humidity around the year, the local climate is typically humid and hot in summer and wet and cold in winter. In this area, the rural buildings are faced with a poor indoor thermal environment. The maximum indoor temperature is generally below $10^{\circ} \mathrm{C}$ in winter and higher than $30^{\circ} \mathrm{C}$ in summer. What is worse, the indoor relative humidity always stays above $50 \%$, whether in winter or summer [14].

In early 2017, our research team surveyed 350 rural households in Hanzhong Prefecture. The survey shows that all residential buildings in this area are built by the villagers based on experience. Without considering the orientation, the villagers simply arranged the buildings along the roads according to the terrain. The shape factor of the buildings falls between 0.5 and 0.8 . Most buildings are single-story earth building or two-story brick-concrete building. Adopted in 51\% of the buildings, the brick-concrete structure is the dominant structural form in newly built residential buildings.

Figure 2 shows a typical brick-concrete building in the study area. In the brick-concrete buildings, the outer walls are usually $240 \mathrm{~mm}$-thick brick walls plastered with $20 \mathrm{~mm}$-thick cement mortar on both sides, the roof is mostly a pitched roof with tiles directly placed on the wood rafter, and the windows often consist of a single layer of glass in an aluminum alloy frame. The window size was designed by the villagers empirically according to specific needs. The WWRs are mostly between 0.2 and 0.3 , below the WWR threshold required for energy-efficient buildings in hot summer and cold winter zone [15].

None of the buildings has an insulated envelope. The heat transfer coefficients are very large in the main parts of the envelope. The villagers have installed curtains inside the windows, without adding external sunshades. The windows are often opened for a long time each day, an evidence for the villagers' heavy dependence on windows. In fact, the WWR tends to increase as people long for a spacious and well-lighted indoor environment.

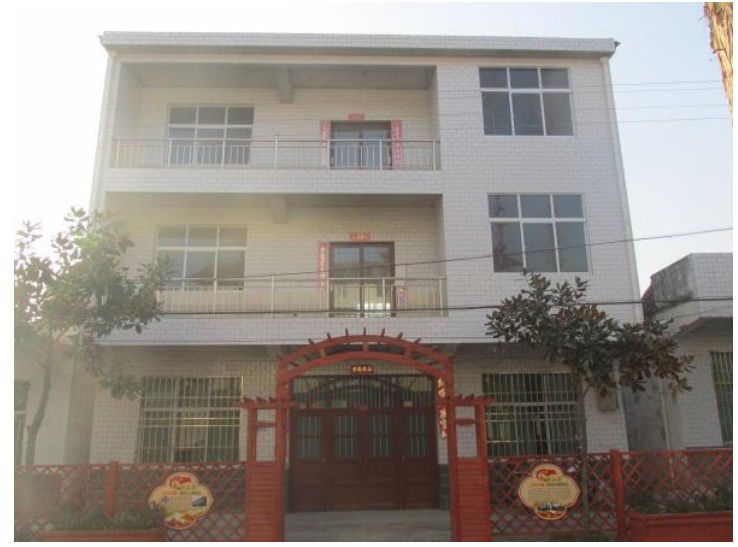

Figure 2. A typical brick-concrete building in the study area

More than half of the surveyed villagers held that it was too cold during the daytime in winter, over $80 \%$ felt that it was too cold during the nighttime in winter, and $85 \%$ considered indoor thermal environment acceptable in summer (less than $20 \%$ of this particular group of villagers felt comfortable). Overall, the indoor thermal environment in winter is not satisfactory to most villagers in the study area, and less desirable than that in summer.

Therefore, it is very possible to improve the indoor environment in the study area, especially in winter. Considering the current status of rural buildings, the villagers' demand for indoor environment and the green development of rural buildings, this paper firstly explores how building energy consumption is affected by the WWR and the thermal performance of the windows. 


\section{BUILDING MODELLING}

Based on the typical brick-concrete building in the study area, a $5 \mathrm{~m} \times 5 \mathrm{~m} \times 3.5 \mathrm{~m}$ model was established. As shown in Figure 3 , the shape factor is 0.63 , the outer walls are ordinary clay brick walls, the roof is an ordinary pitched roof with a single layer of grey clay tiles, and the windows consist of either a single layer of glass or double layers of glass in an aluminum alloy frame. The parameters of each component are listed in Table 1.

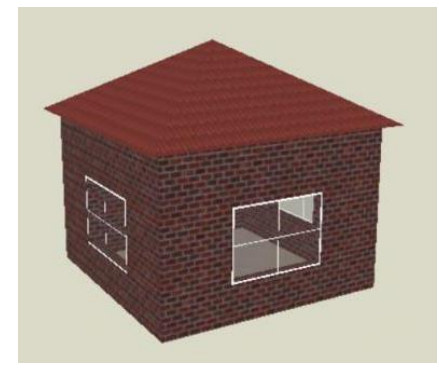

Figure 3. Model of a typical building

Table 1. Component and thermal performance of the building envelope in the model

\begin{tabular}{ccc}
\hline Building envelope & components & $\begin{array}{c}\text { Heat transfer coefficient } \\
\left(\mathrm{W} /\left(\mathrm{m}^{2} \cdot \mathrm{K}\right)\right)\end{array}$ \\
\hline External walls & $20 \mathrm{~mm}$ cement mortar $+240 \mathrm{~mm}$ clay bricks $+20 \mathrm{~mm}$ cement mortar & 1.93 \\
\hline Roof & $20 \mathrm{~mm}$ grey clay tiles & 0.93 \\
\hline Single-layer window & Aluminum alloy frame + single layer of 6 mm glass & 6.4 \\
\hline Double-layer window & Aluminum alloy frame + double layers of 6 mm glass & 3.9 \\
\hline
\end{tabular}

The outdoor thermal environmental parameters were extracted from those of the typical meteorological year of Hanzhong, and those for indoor were obtained from References [15-18] for model calculation. In addition, the indoor temperatures in winter and summer were respectively designed as $14^{\circ} \mathrm{C}$ and $28^{\circ} \mathrm{C}$, considering the impacts of winter heating and summer cooling in main rooms of rural buildings (e.g. bedrooms and living room). The heating period was designated to last from December 1 of the current year to February 28 of the following year, while the cooling period from June 15 to August 31 of the current year. During heating and cooling, the ventilation rate was selected as 1.0 time/h.

During the simulation, a window was opened in the external walls facing the east, west, south and north in turns. In light of the local situation and Reference $[7,15,16]$, the WWR was set to $0.2 \sim 0.8$ and increased by 0.1 in each simulation. The building simulation software of DesignBuilder developed by Design Builder Company in the UK was adopted to dynamically simulate the annual total energy consumption of the target building, as well as the annual energy consumed for cooling and heating. The energy consumption was evaluated by the energy consumption value per unit building area. The energy consumption index was expressed by power consumption.

\section{RESULTS AND DISCUSSION}

\subsection{Cooling energy consumption}

Based on the dynamic analysis of annual cooling energy consumption, the relationships between cooling energy consumption and the WWR of different orientations are plotted as Figure 4.

As shown in Figure 4, the cooling energy consumption increased linearly with the growth of the WWR, whichever the orientation, when the windows had different thermal performances. The above changing trend with WWR is consistent with that in the three typical cities (Chongqing, Shanghai, and Wuhan) in hot summer and cold winter zone in China [19]. The continuous growth in cooling energy consumption is attributable to the strong capacities of glass in solar radiation transmission and heat transfer. Due to these capacities, the larger the window size, the more the solar heat penetrates through the glass into the room in summer. Thus, it takes more and more energy to cool down the indoor environment. Hence, the WWR in any of the four orientations should be minimized to reduce the cooling energy consumption per unit building area.

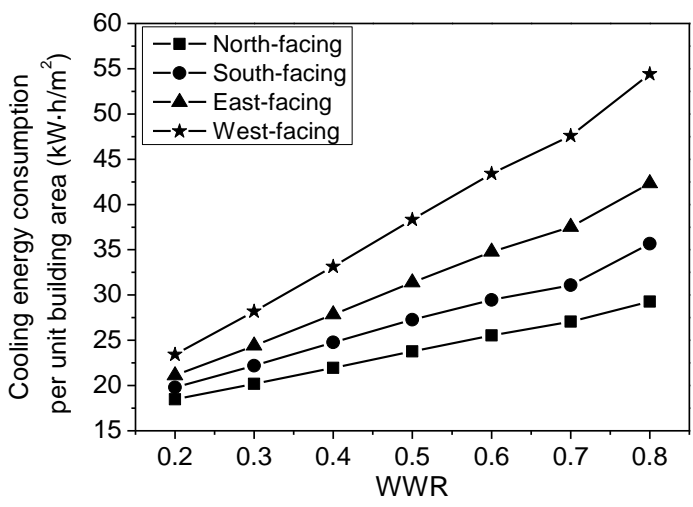

(a) Single-layer window

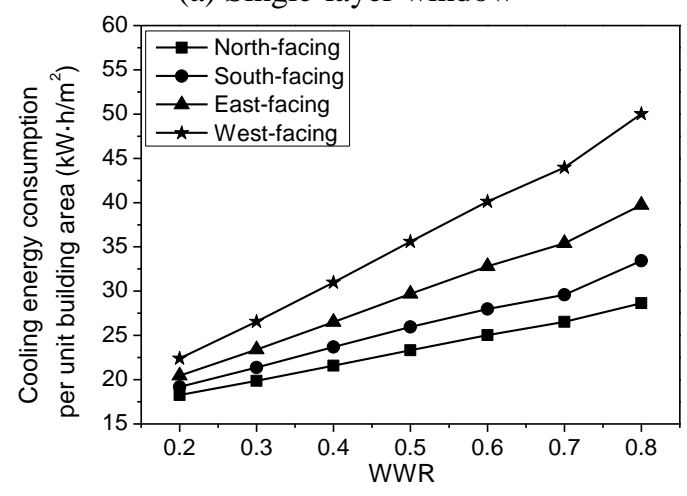

(b) Double-layer window

Figure 4. Relationships between cooling energy consumption and the WWR of different orientations

The variation in the WWR of different orientations induced varied degrees of changes to cooling energy consumption. The west-facing WWR had the greatest impact on cooling energy consumption, followed in descending order by the east-facing WWR, the south-facing WWR and the north-facing WWR. When the north-, south-, east- and west-facing WWRs grew from 0.2 to 0.8 , the cooling energy consumption increased by 
$58 \%, 80 \%, 101 \%$ and $132 \%$, respectively, when using the single-layer window, and increased by 57\%, 74\%, 94\% and $109 \%$, respectively, when using the double-layer window.

Overall, a 0.1 increment in the north-, south-, east- and west-facing WWRs caused an increment of $8 \%, 10 \%, 12 \%$ and $15 \%$, respectively, in cooling energy consumption, when using the single-layer window, and an increment of $8 \%, 10 \%, 12 \%$ and $14 \%$, respectively, in cooling energy consumption, when using the double-layer window. Therefore, the size expansion of north-facing window has the least impact on the cooling energy consumption in summer, while that of west-facing window has the greatest impact.

After replacing single-layer window with double-layer window (i.e. reducing the heat transfer coefficient of the window), the cooling energy consumption decreased under the WWR of any orientation. The decrement is proportional to the WWR. However, the absolute value of the decrement is small. As shown in Figure 5, under the WWR of 0.2, the cooling energy consumption dropped by $1.1 \%, 3.0 \%, 3.1 \%$ and $4.4 \%$, respectively, after the single-layer window was replaced by the double-layer window in the north, south, east and west orientations; under the WWR of 0.8 , the cooling energy consumption dropped by $2.2 \%, 6.3 \%, 6.2 \%$ and $8.1 \%$, respectively, after the replacement. It can be seen that the cooling energy consumption was only slightly affected by changing the heat transfer coefficient of the north-facing window, and greatly affected by changing that coefficient of the west-facing window. When the WWR varied in $0.2 \sim 0.8$, the cooling energy consumption changed by less than $8.1 \%$, as the heat transfer coefficient of the window dropped from 6.4 $\mathrm{W} /\left(\mathrm{m}^{2} \cdot \mathrm{K}\right)$ to $3.9 \mathrm{~W} /\left(\mathrm{m}^{2} \cdot \mathrm{K}\right)$.

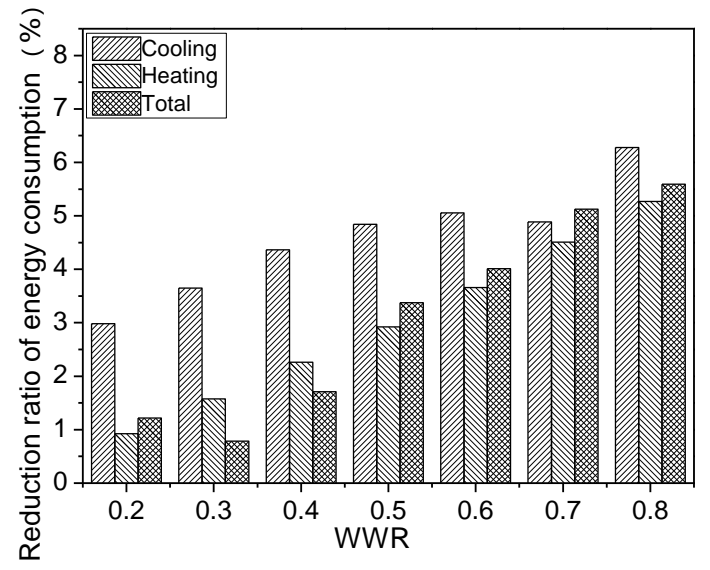

(a) South-facing

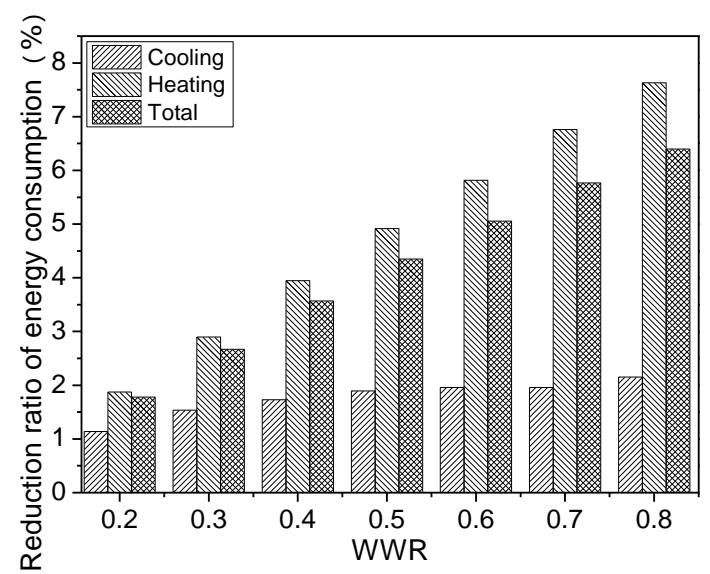

(b) North-facing

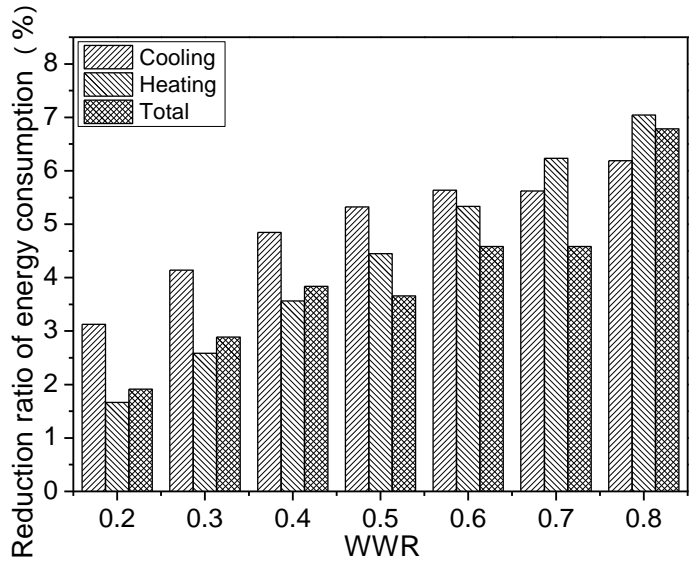

(c) East-facing

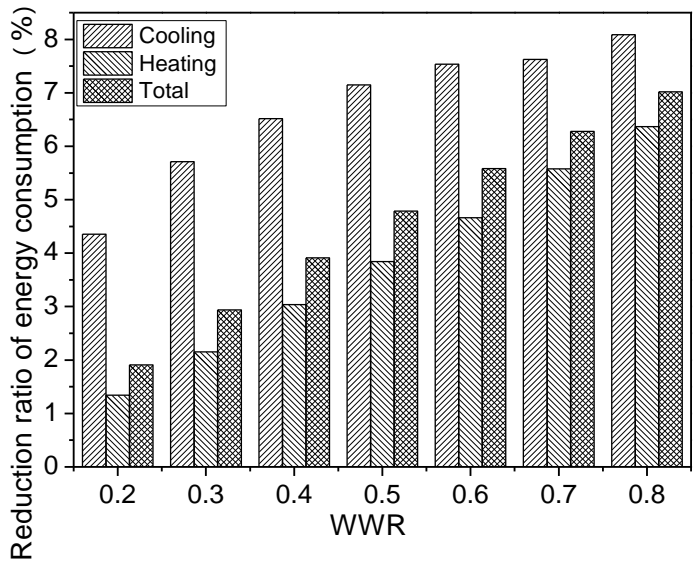

(d) West-facing

Figure 5. Reduction ratio of energy consumption when single-layer window is replaced by double-layer window

\subsection{Heating energy consumption}

Based on the dynamic analysis of annual heating energy consumption, the relationships between heating energy consumption and the WWR of different orientations are plotted as Figure 6.

As shown in Figure 6, the heating energy consumption showed a slight, linear decrease with the growth in the WWR, when the windows had different thermal performances. The variation trend of the heating energy consumption with WWR is similar to that in Shanghai and Wuhan [19]. The gradual decline in heating energy consumption per unit building area can be explained as follows. The study area has sufficient solar radiation in winter. During this season, the heat entering the room through the window is greater than the heat loss caused by cold air infiltration via the window. In this case, the window is a heat gain component. The greater the window size, the more external heat entering the room.

The variation in the WWR of different orientations induced varied degrees of decrease to heating energy consumption. The south-facing WWR had the greatest impact on heating energy consumption, followed in descending order by the west-facing WWR, the east-facing WWR and the north-facing WWR. When the south-, west-, east- and north-facing WWRs grew from 0.2 to 0.8 , the heating energy consumption decreased by $16 \%, 11 \%, 6 \%$ and $3 \%$, respectively, when using the singlelayer window, and decreased by $20 \%, 15 \%, 11 \%$ and $9 \%$, respectively, when using the double-layer window. 


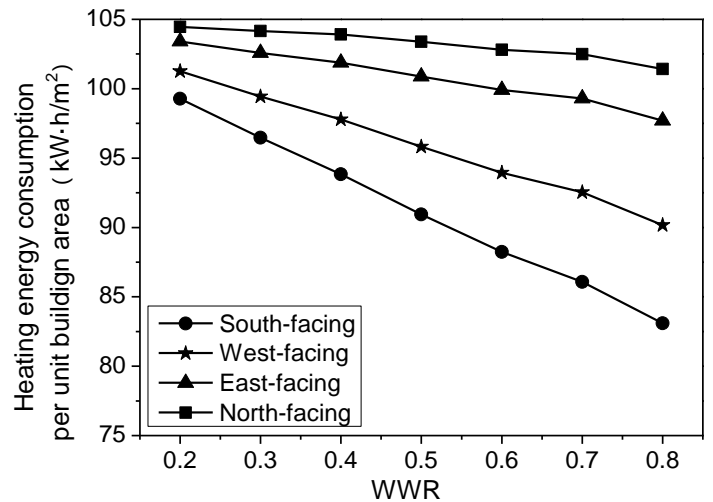

(a) Single-layer window

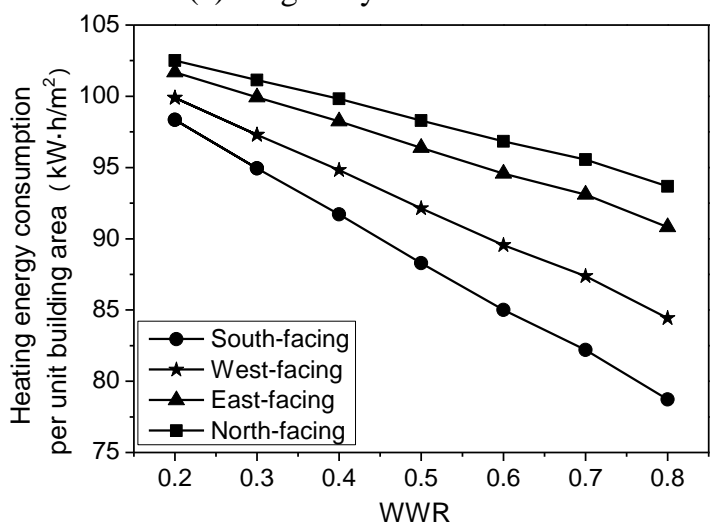

(b) Double-layer window

Figure 6. Relationships between heating energy consumption and the WWR of different orientations

Overall, a 0.1 increment in the south-, west-, east- and north-facing WWRs caused a decrement of $3 \%, 2 \%, 1 \%$ and $0.5 \%$, respectively, in heating energy consumption, when using the single-layer window, and a decrement of $4 \%, 3 \%$, $2 \%$ and $1 \%$, respectively, in heating energy consumption, when using the double-layer window. Therefore, the size expansion of south-facing window has the greatest impact on the heating energy consumption in winter, while that of northfacing window had the least impact.

After replacing single-layer window with double-layer window, the heating energy consumption decreased slightly under the WWR of any orientation. The decrement is proportional to the WWR. As shown in Figure 5, under the WWR of 0.2 , the heating energy consumption dropped by $0.9 \%, 1.3 \%, 1.7 \%$ and $1.9 \%$, respectively, after the singlelayer window was replaced by the double-layer window in the south, west, east and north orientations; under the WWR of 0.8 , the heating energy consumption dropped by $5.3 \%, 6.4 \%$, $7.0 \%$ and $7.6 \%$, respectively, after the replacement. As a result, the heating energy consumption was only slightly affected by changing the heat transfer coefficient of the southfacing window, and greatly affected by changing that coefficient of the north-facing window. When the WWR varied in $0.2 \sim 0.8$, the heating energy consumption changed by less than $7.6 \%$ as the heat transfer coefficient of the window dropped from $6.4 \mathrm{~W} /\left(\mathrm{m}^{2} \cdot \mathrm{K}\right)$ to $3.9 \mathrm{~W} /\left(\mathrm{m}^{2} \cdot \mathrm{K}\right)$.

\subsection{Total energy consumption}

Based on the dynamic analysis of annual total energy consumption, the relationships between the total energy consumption and the WWR of different orientations are plotted as Figure 7.

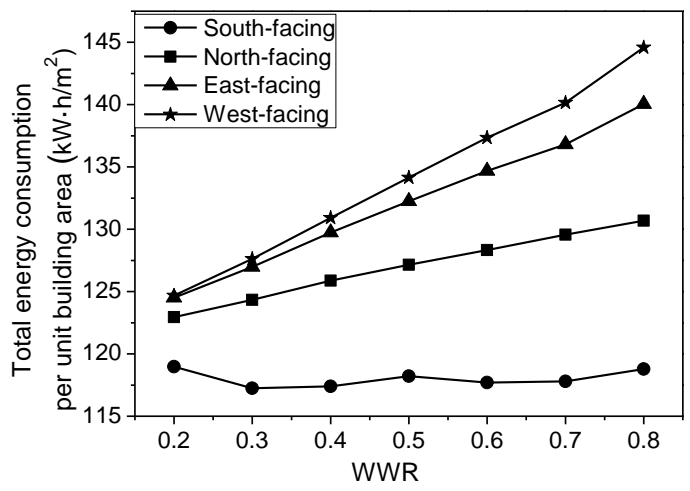

(a) Single-layer window

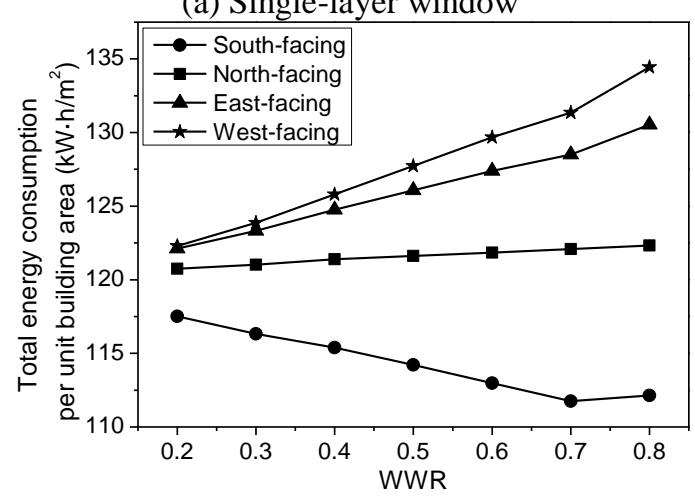

(b) Double-layer window

Figure 7. Relationships between total energy consumption and the WWR of different orientations

As shown in Figure 7, the total energy consumption exhibited different change laws with the growth in the WWRs of different orientations. The variation trend of the total energy consumption with WWR is analogous to that in Chongqing, Shanghai and Wuhan. The total energy consumption decreased first and then increased with the increase of the south-facing WWR, but the overall change was limited. When using the single-layer window, the total energy consumption changed by less than $1 \%$ as the WWR ranged between 0.3 and 0.7; when using the double-layer window, the total energy consumption was minimized at the WWR of 0.7 .

As for north-, east- and west-facing WWRs, the total energy consumption continued to rise with the increase of each WWR. As the north-, east- and west-facing WWRs grew from 0.2 to 0.8 , the total energy consumption increased by $6 \%, 12 \%$ and $16 \%$, respectively, when using the single-layer window, and by $13 \%, 7 \%$ and $10 \%$, respectively, when using the doublelayer window. Overall, a 0.1 increase in the north-, east- and west-facing WWRs caused an increment of $1 \%, 2 \%$ and $3 \%$, respectively, in total energy consumption, when using the single-layer window, and an increment of $0.2 \%, 1.4 \%$ and $1.6 \%$ respectively, in total energy consumption, when using the double-layer window. To sum up, the total energy consumption was more affected by the variation in east- and west-facing WWRs than that in south- and north-facing WWRs.

The above finding is the result of the following reasons: Firstly, the absolute value of heating energy consumption is far greater than that of cooling energy consumption. As shown in Figure 8, cooling energy consumption accounted for a small portion in the total energy consumption, which gradually increased with the WWR. Secondly, the cooling energy 
consumption increased significantly, while the heating energy consumption decreased slightly, compared with the total energy consumption at the WWR of 0.2. By the impact on cooling energy consumption, the WWR in different orientations can be ranked in descending order as south-facing, east-facing, north-facing and south-facing. By the impact on heating energy consumption, the WWR in different orientations can be ranked in descending order as south-facing, west-facing, east-facing and north-facing. Hence, the total energy consumption was slightly affected by the south-facing WWR and greatly by the west-facing WWR.

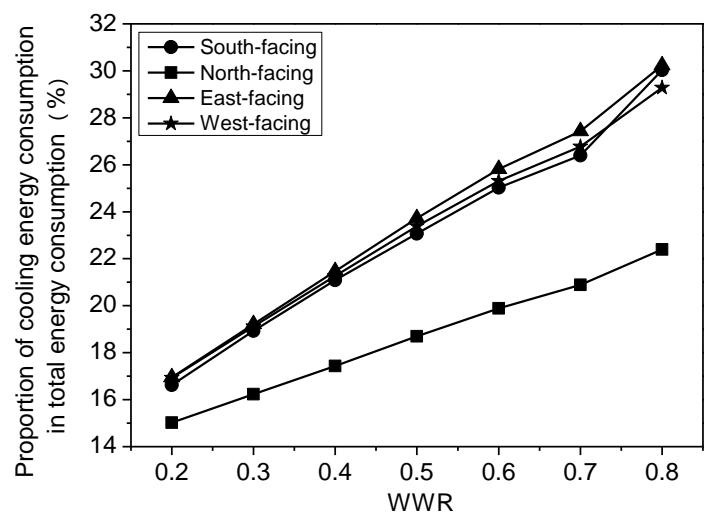

(a) Single-layer window

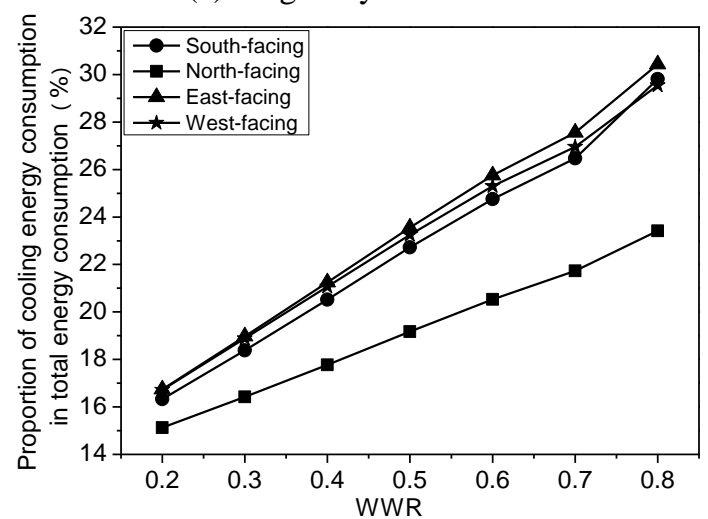

(b) Double-layer window

Figure 8. Proportion of cooling energy consumption in total energy consumption

After replacing single-layer window with double-layer window (i.e. enhancing the thermal performance of the window), the total energy consumption decreased under the WWR of any orientation. The decrement is proportional to the WWR. As shown in Figure 8, under the WWR of 0.2, the total energy consumption dropped by $1.2 \%, 1.8 \%, 1.9 \%$ and $1.9 \%$, respectively, after the single-layer window was replaced by the double-layer window in the south, north, east and west orientations; under the WWR of 0.8 , the total energy consumption dropped by $5.6 \%, 6.4 \%, 6.8 \%$ and $7.0 \%$, respectively, after the replacement. It can be seen that the total energy consumption was only slightly affected by changing the heat transfer coefficient of the south-facing window, and greatly affected by changing that coefficient of the west-facing window. When the WWR varied in $0.2 \sim 0.8$, the total energy consumption changed by less than $7.0 \%$ as the heat transfer coefficient of the window dropped from $6.4 \mathrm{~W} /\left(\mathrm{m}^{2} \cdot \mathrm{K}\right)$ to 3.9 $\mathrm{W} /\left(\mathrm{m}^{2} \cdot \mathrm{K}\right)$.

For the south-facing window, the total energy consumption was small as the WWR fluctuated in $0.3 \sim 0.7$, when using the single-layer window. In this case, the total energy consumption changed by less than $0.7 \%$ for each 0.1 variation in the WWR. Meanwhile, the total energy consumption was minimized at the WWR of 0.7 , when using the double-layer window, and the total energy consumption changed by less than $1.1 \%$ for each 0.1 variation in the WWR. To minimize the total energy, the south-facing window in the study area should be designed with the WWR between 0.3 0.7. In addition, the total energy consumption was slightly affected by the north-facing WWR and greatly by the west-facing WWR.

\section{CONCLUSIONS}

After investigating the current status of rural buildings in Hanzhong Prefecture, the author set up a calculation model for the typical brick-concrete residential building in that area. The outdoor thermal environmental parameters were extracted from those of the typical meteorological year of Hanzhong for calculation, the indoor heating temperature in winter was set to $14^{\circ} \mathrm{C}$, and the indoor cooling temperature in summer was set to $28^{\circ} \mathrm{C}$. During the simulation, the WWR of different orientations was changed in turns and the heat transfer coefficient of the window was adjusted, and the annual cooling, heating and total energy consumptions of the model was dynamically analyzed by software of DesignBuilder. Through the analysis, the main conclusions were drawn as follows:

(1) With the increase of the WWR of any orientation, the cooling energy consumption increased, the heating energy consumption decreased. The total energy consumption increased with growth of the north-, east- and west-facing WWRs, but increased and then decreased with growth of the south-facing WWR.

(2) The north-facing WWR has the least impact on the cooling energy consumption in summer, while the west-facing WWR has the greatest impact. The south-facing WWR has the least impact on the heating energy consumption in winter, while the north-facing WWR has the greatest impact. The south-facing WWR has the least impact on total energy consumption, while the west-facing WWR has the greatest impact. Therefore, the optimal window orientation in the study area should be south, north, east and west.

(3) In order to save energy, the south-facing WWR should fall within $0.3 \sim 0.7$, the east-facing WWR should stay below 0.7 , and the west-facing wall should not have any window or have a small window.

(4) The cooling, heating and total energy consumptions are reduced by lowering the heat transfer coefficient of the window. The reduction is proportional to the WWR. It is possible to save much energy by opening a window with a small heat transfer coefficient in the east or west orientation. However, the energy conservation effect is limited by opening the same window in the south and north orientation.

\section{ACKNOWLEDGMENT}

The research is financially supported by the Natural Science Foundation of China (NSFC grant no: 51678483).

\section{REFERENCES}

[1] Lin, T., Cao, M.R. (2004). Talk about the energy- 
conservation design of the doors and windows in the area. Chinese \& Overseas Architecture, 102-105. http://dx.doi.org/10.3969/j.issn.1008-0422.2004.03.036

[2] Huang, Y.C., Zheng, B.F. (2014). Energy-conservation design of doors and windows in hot summer and cold winter zone. Doors \& Windows, 06: 192-194.

[3] Xiong, G.W. (2013). Influence of window-wall ratio and shading on the total energy consumption of residential heating and air conditioning. Building Energy Efficiency, 10: 44-46.

[4] He, S.Q., Wei, D.L. (2007). The influencing factor of energy-saving window and hollow glass window deployment. Doors \& Windows, (5): 3-9. http://dx.doi.org/10.3969/j.issn.1673-8780.2007.05.002

[5] Wang, J.K., Shi, H.F. (2010). The application of area ratio of window to wall in energy efficiency design of public building. Low Temperature Architecture Technology, 32(9): 102-103. http://dx.doi.org/10.3969/j.issn.1001-6864.2010.09. 042

[6] Mostafaei, A., Mirrzaei, M., Ghazvini, M., Ahmadi, M.H., Lorenzini, G. (2019). Investigation of energy saving in building by using phase-change materials (PCM). Mathematical Modelling of Engineering Problems, 6(1): 47-51. https://doi.org/10.18280/mmep.060106

[7] Fan, X.H., Zhang, Z.C., Wang, J., Yang, F. (2017). Multi-objective optimal design of the window size about village and town building in hot summer and cold winter area. Building Energy Efficiency, 45(12): 80-84. http://dx.doi.org/10.3969/j.issn.1673-7237.2017.12.018

[8] Jian, Y.W., Jiang, Y. (2006). Influence of window wall ratio on annual energy consumption for heating and air conditioning in residential buildings. Heating Ventilating \& Air Conditioning, 36(6): 1-5. http://dx.doi.org/10.3969/j.issn.1002-8501.2006.06.001

[9] Yan, C.W., Yao, J., Zhou, Y., Zhang, W.H. (2007). Effects on residential buildings from area ratio of window to wall in hot summer and cold winter zone. Doors \& Windows, (05): 1-3. http://dx.doi.org/10.3969/j.issn.1673-8780.2007.05.001

[10] Chen, G., Meng, Q.M., Cao, J., Wang, D.W. (2007). Effect of exterior wall structure and area ratio of window to wall on heating energy consumption and PMV of frequency conversion air-condition room. Energy Conservation Technology, 25(6): 489-492, 557. http://dx.doi.org/10.3969/j.issn.1002-6339.2007.06.003

[11] Meng, E.L., Wang, Z.J., Zhang, Y. (2008). The impact on residential energy consumption by heat transfer coefficient of window, area ratio of windows and wall. Energy Conservation, (3): 38-40. http://dx.doi.org/10.3969/j.issn.1004-7948.2008.03.013

[12] Cheng, H., Feng, X.P., Wang, Y. (2011). Influences of window-wall ratio on annual energy consumption for heating and air conditioning in residential buildings in southern region of Jiangsu. Building Energy Efficiency, 39(11): 54-57. http://dx.doi.org/10.3969/j.issn.16737237.2011 .11 .014

[13] Jiang, D.M. (2009). Influence of window-wall ratio on annual energy consumption in residential buildings. Architecture Technology, 40(12): 1099-1102. http://dx.doi.org/10.3969/j.issn.1000-4726.2009.12.012

[14] Zhu, Y.Y., Liu, P.C., Sang, G.C., Zhao, Q. (2016). Study and measurement of thermal environment of rural civilian dwelling in Qinba mountain areas of southern Shaanxi province. Acta Energiae Solaris Sinica, 37(4): 957-962. http://dx.doi.org/10.3969/j.issn.0254-0096. 2016.04.023

[15] Professional standard of the People's Republic of China, JGJ134-2010 Design standard for energy efficiency of residential buildings in hot summer and cold winter zone. Beijing: China Architecture \& Building Press, 2010

[16] National standards of People's Republic of China, GB/T 50824-2013, Design standard for energy efficiency of rural residential buildings. Beijing: China Architecture \& Building Press, 2013.

[17] Sil, I., Mukherjee, S., Biswas, K. (2017). A review of energy harvesting technology and its potential applications. Environmental and Earth Sciences Research Journal, 4(2): 33-38. https://doi.org/10.18280/eesrj.040202

[18] Cheng, F., Zhang, X., Su, X., Li, Y.H. (2016). Discussion for air-conditioning design temperatureof passive residential building in hot summer and cold winter area. Building Technology Development, 43(2): 7-9. http://dx.doi.org/10.3969/j.issn.1001-523X.2016.02.002 